\title{
DROP TEST SIMULATION ON PEN DRIVE BY USING ANSYS
}

\author{
Mohammed Imran ${ }^{1}$, Chandan $M^{2}$, Bharath $B S^{3}$, Yeshawanth $S^{4}$ \\ ${ }^{1}$ Assistant Professor, Department of Mechanical Engineering, Ghousia College of Engineering-Ramanagaram- \\ 562159, Banglore, Karnataka, India \\ ${ }^{2}$ B.E Student, Department of Mechanical Engineering, Ghousia College of Engineering-Ramanagaram-562159, \\ Banglore, Karnataka, India \\ ${ }^{3}$ B.E Student, Department of Mechanical Engineering, Ghousia College of Engineering-Ramanagaram-562159, \\ Banglore, Karnataka, India \\ ${ }^{4}$ B.E Student, Department of Mechanical Engineering, Ghousia College of Engineering-Ramanagaram-562159, \\ Banglore, Karnataka, India
}

\begin{abstract}
Stress is plays an important role in a structural safety of the component and integral assemblies. Structural analysis comprises the set of physical laws and mathematics required to study and predict the behavior of structures. In the present work, Drop test analysis on a pen-drive with different materials is carried out using ANSYS, to evaluate the structural safety of component, when pen-drive is falling on ground with random velocity. Developing CAD model, meshing and results are analyzed by using ANSYS. Dimensions of pen-drive are considered with respect to industrial standards. Material properties are selected as per the ASTM standard (A36). This work comes under two categories. Initially carbon steel is used for the drop test analysis. Later carbon steel is replaced by kinematic inelastic material (Plastic material) to find the structural safety of component under drop test boundary conditions. Finally results are comparing with both materials value.
\end{abstract}

Keywords: Pendrive model, Steel and kinematic bilinear materials, structural safety, and ANSYS.

\section{INTRODUCTION}

The structural analysis of engineering components whose integrity based upon their ability to withstand loads which in turns to structural safety of component. In the present work, Drop test analysis on a pen-drive with different materials is carried out using ANSYS.

John Higgins [1], presented a seminar on prop test simulation using ANSYS. They are considering shock spectrum boundary condition for drop test simulation. The model is used to analyzed as CD, DVD Disc, gas cylinder, mobile, electronic devices and golf ball etc, under the shock spectrum loading condition. Drop test or impact analysis [2], shows in the website drop testing is a simulation analysis to predict critical condition of components, under damage criterion. This analysis simulation is to produce the model capable of predicting stress and strain components there by same production time and expanses. Drop test using LSDYNA [3], examples are used to practices drop test analysis in a LS-DYNA and getting the concept to solve the present work. From the website [4], ball drop on composite fiber impact analysis using LS-DYNA.

\section{PROBLEM DEFINITION AND SCOPE OF} PRESENT WORK

\subsection{Problem Definition}

$>$ Drop test analysis on a pen-drive using ANSYS with different material.

$>$ Developing CAD model, meshing and results are analyzed by using ANSYS.

$>\quad$ These work is comes under two categories based on type of material.

i. Mild steel material is used to analyze structure safety of component.

ii. Kinematic bilinear material will be used to analyze structural safety of component.

\subsection{Methodology}

$>$ Dimensions of pen-drive are taking form industrial standards.

$>$ Material properties are selected as per the ASTM standard (A36)

$>$ Modeling, meshing, applying boundary conditions and results are analyzing the structural safety of component using ANSYS

$>$ Initially carbon steel is used for the drop test analysis.

$>$ Later carbon steel material is replaced by kinematic inelastic material (Plastic material) to find the structural safety of component under drop test boundary conditions.

$>$ Finally correlating resultant value of both materials by considering same boundary condition and same design.

\subsection{Specification}

Structure

Meshing
: Shell 163
: Map meshing- 4-noded
quadrilateral meshing 
Number of element division

Boundary condition

Time taken

Material properties
$: 3$

:Initial velocity $100 \mathrm{~m} / \mathrm{s}$

$: 1 \mathrm{~min}$

: Using two materials as follows

\section{- First material Properties}

Mild steel material is used for both pen drive which is plastic in nature and a platform, on to which the pen drive falls with a velocity $-100 \mathrm{In} / \mathrm{sec}$ as shown in the table-1

- Second material Properties

Bilinear kinematic material is used for pen drive which is plastic in nature and a platform (Rigid element) is made by a steel material, on to which the pen drive falls with a velocity $-100 \mathrm{In} / \mathrm{sec}$ as shown in the table-1

Table-1: Material Properties as per the ASTM Standard

\begin{tabular}{|c|c|}
\hline Pen-drive Material & $\begin{array}{l}\text { Platform Martial } \\
\text { (Rigid element) }\end{array}$ \\
\hline 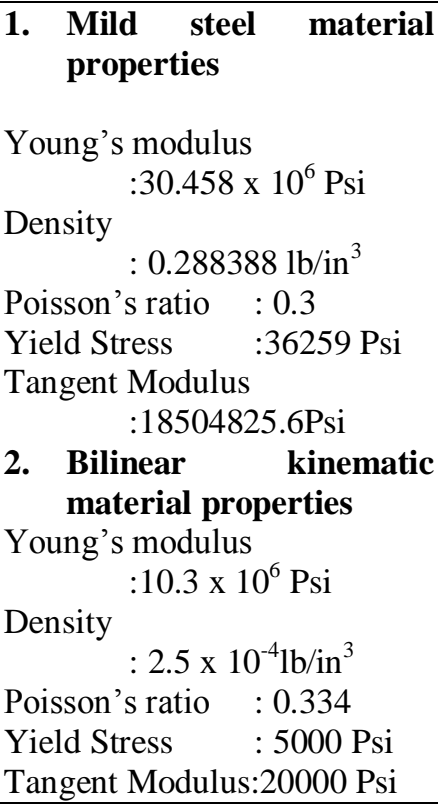 & $\begin{array}{l}\text { Steel martial properties } \\
\text { Young's modulus } \\
\qquad: 3 \times 10^{7} \mathrm{Psi} \\
\text { Density } \\
\quad: 7.85 \times 10^{-4} \mathrm{lb} / \mathrm{in}^{3} \\
\text { Poisson's ratio }: 0.292\end{array}$ \\
\hline
\end{tabular}

\subsection{Assumption}

$>$ Assuming negligible Thickness of the pen-drive

$>$ Properties of Materials will be considered as nonlinear elastic and plastic material.

$>$ Loads are assumed transient before and after drop.

$>$ Drop height is approximated as 20 feet

\subsection{Modeling}

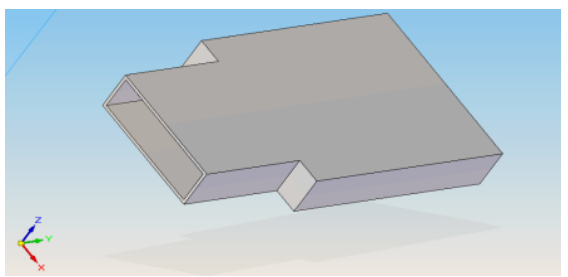

Fig-2: 3-Dimensional CAD-Model of pen drive (Note: All dimensions are in inch).

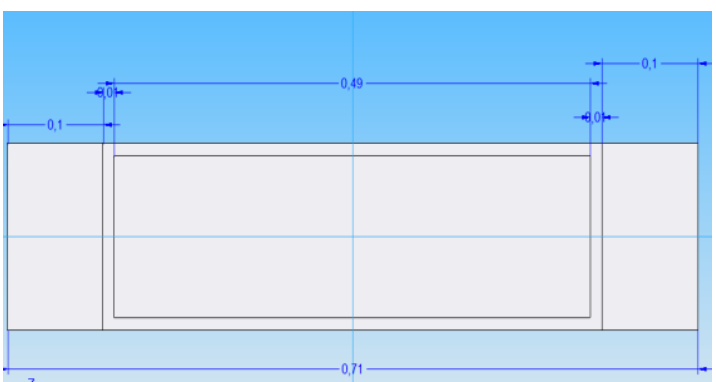

Fig-2 (a): Front view

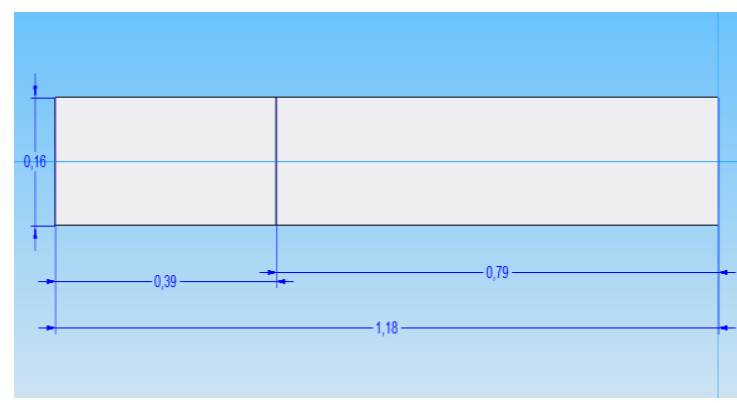

Fig-2 (b): Side view

Fig-2 shows, 3-dimensional CAD-model of pen drive with negligible thickness [approximately $0.3 \mathrm{~mm}$ ], model is developed by using ANSYS work-bench.Fig-2 (a) \& (b) shows front $\&$ side views with the dimensions.

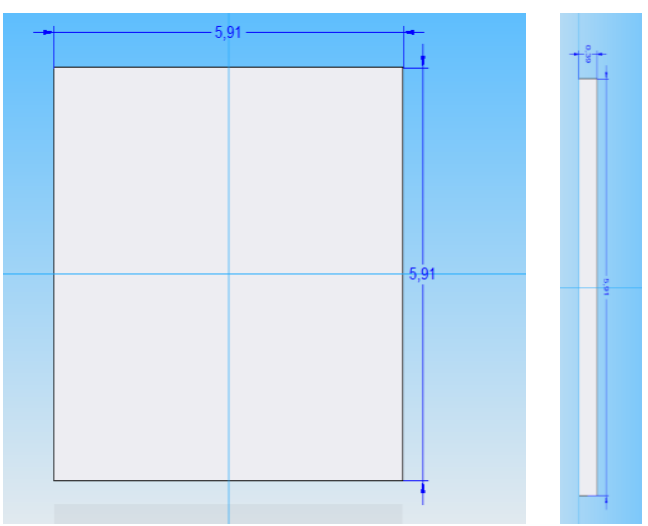

Fig-3:3-Dimensional CAD-model of platform (Rigid Element).

Fig-3 shows, 3-dimensional CAD-model of platform with thickness $5 \mathrm{~mm}$, model is developed by using ANSYS work-bench. 


\subsection{Mesh Plot}

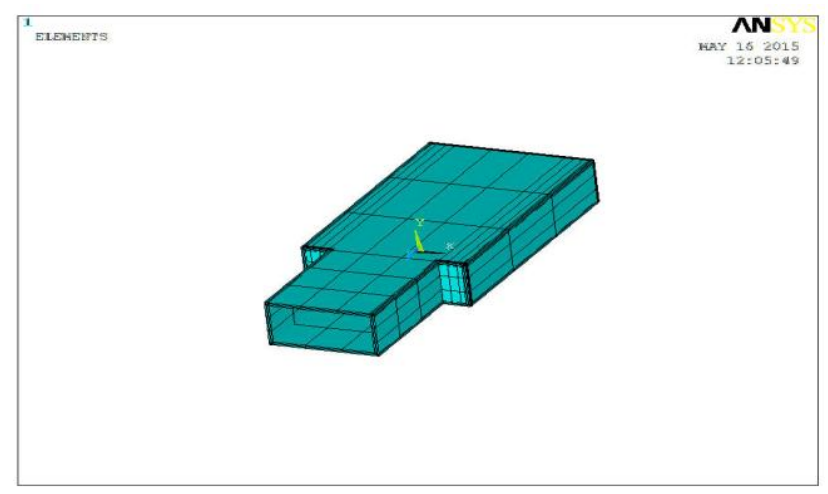

Fig-4:3-Dimensional mesh element (Pen-drive).

Fig -4 shows mesh model of shell 163 element (Pen-drive) in ANSYS. Mesh plot is shows that quadrilateral 4-noded map meshing element. It gives the 797 elements are discretized and800number of nodes are developed after meshing for pen drive.

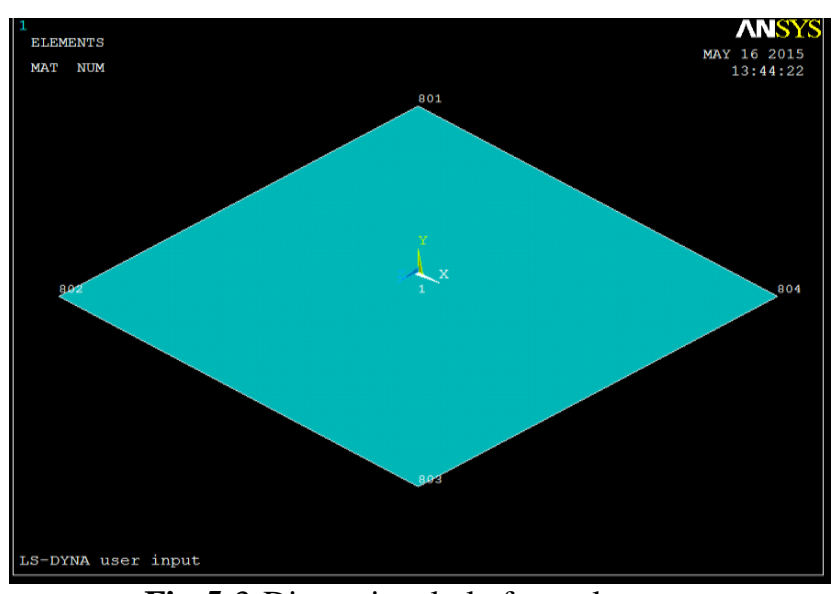

Fig-5:3-Dimensional platform element.

Fig-5 shows target called plot form develop by 4-nodes that is $801,802,803,804$ and is consider as a shell 163 element.

\subsection{Boundary Condition}

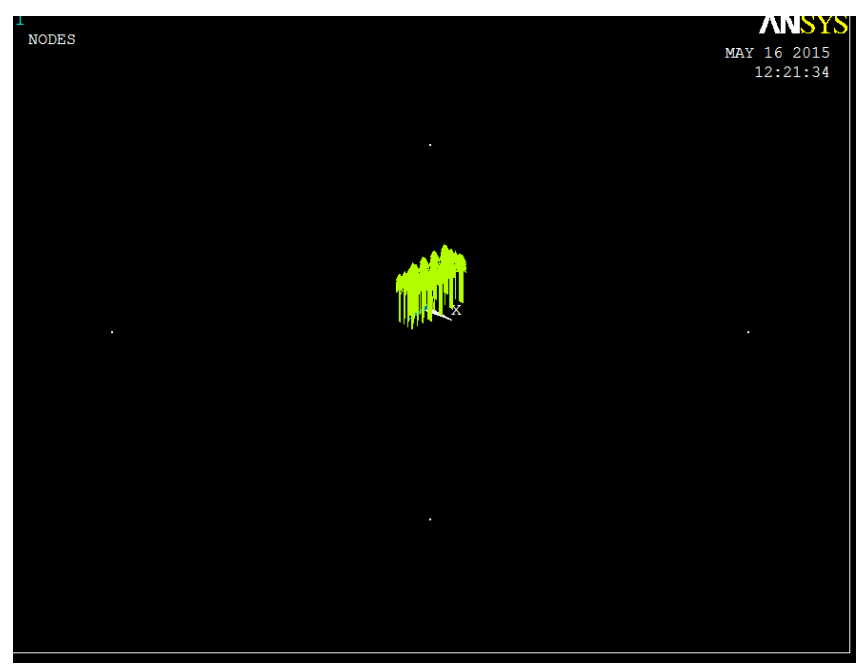

Fig-6: Boundary Conditions.
Fig-6 shows boundary condition is applied as initial velocity of element is -100 inch per second with respect to Time $\mathrm{t}=1 \mathrm{~min}$.

\section{RESULTS AND DISCUSSION}

\subsection{CASE-1: Drop Test Analysis on Mild Steel}

\section{Material for Both Components}

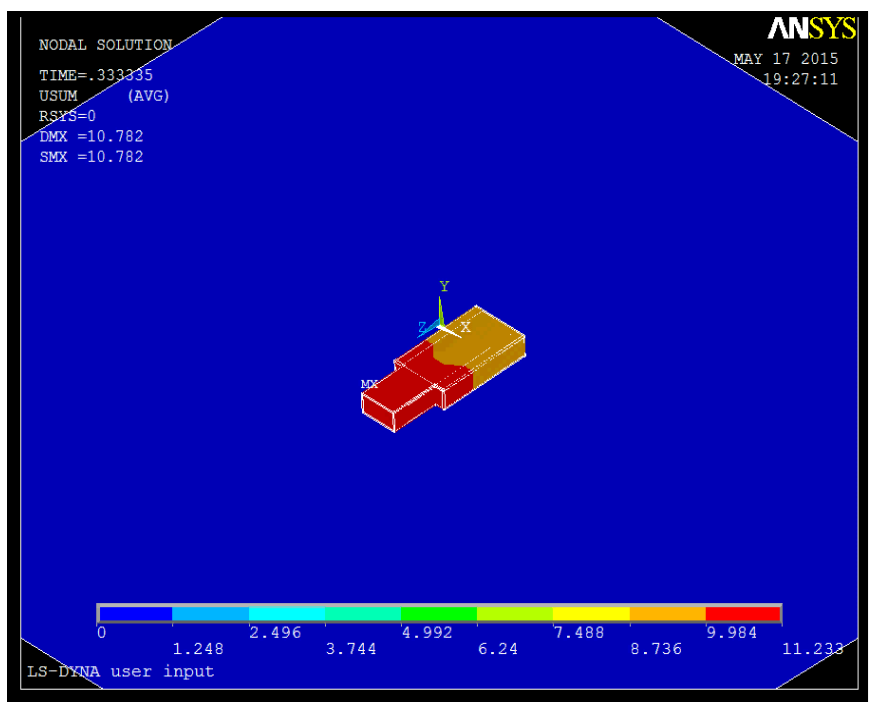

Fig-7: Displacement of Component

Fig -7, shows the maximum displacement of the component is $11.233 \times 10^{-2}$ inch $(0.0044 \mathrm{~mm})$ of initial velocity -100 $\mathrm{inch} / \mathrm{sec}$ is falling on the plot form.

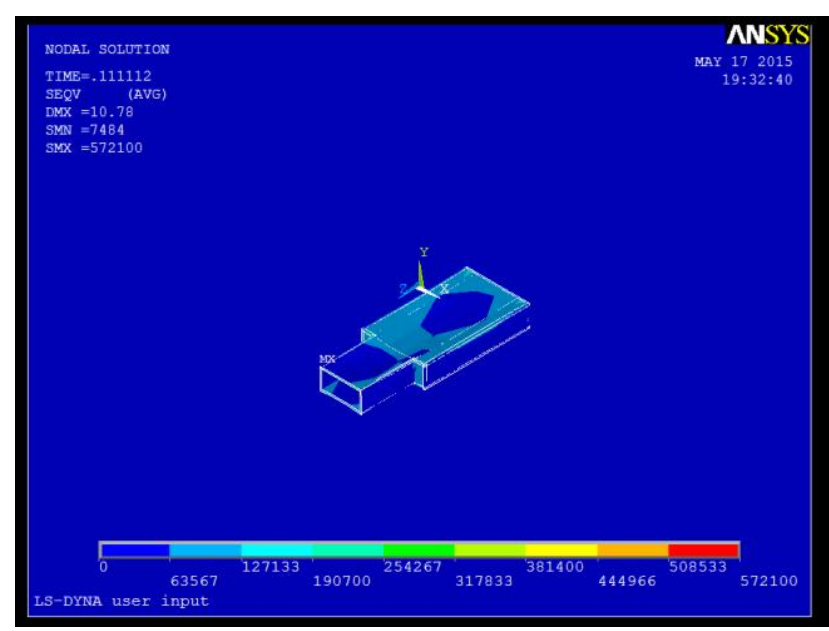

Fig-8: Stress Distribution of Component

Fig -8 shows the maximum stress distribution in a component is $572100 \mathrm{psi}$ at initial velocity $-100 \mathrm{inch} / \mathrm{sec}$ is falling on the plot form. 


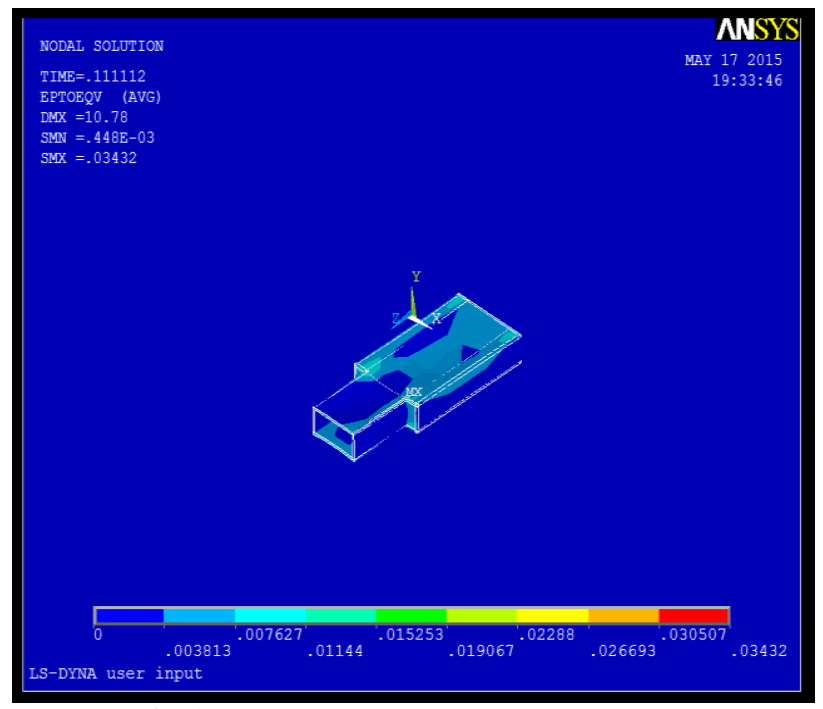

Fig-9: Strain Distribution of Component

Fig -9 shows the maximum strain distribution in a component is 0.03432 at initial velocity $-100 \mathrm{inch} / \mathrm{sec}$ is falling on the plot form.

\section{Graphs}

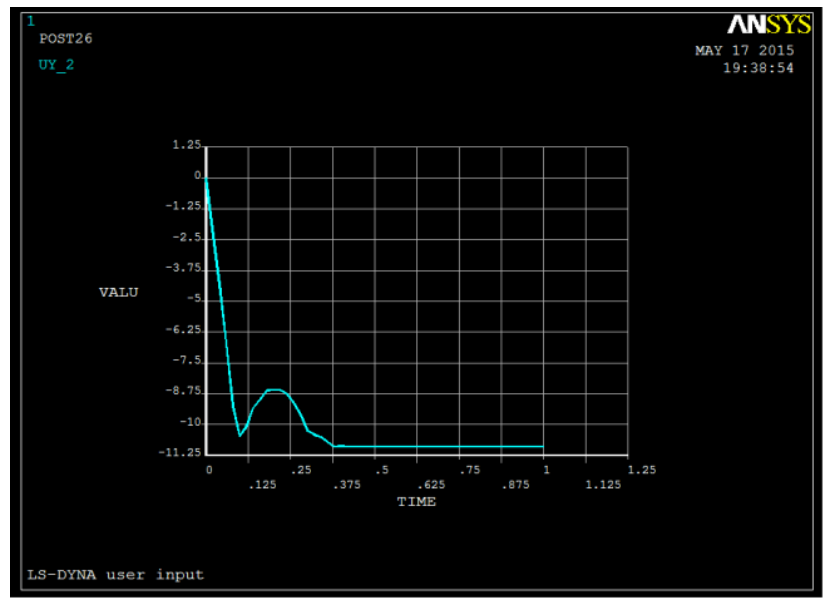

Fig-10: Displacement Graph of Component

Graph shows in Fig 10, maximum displacement takes place due to random velocity in negative y-axis based on design model.

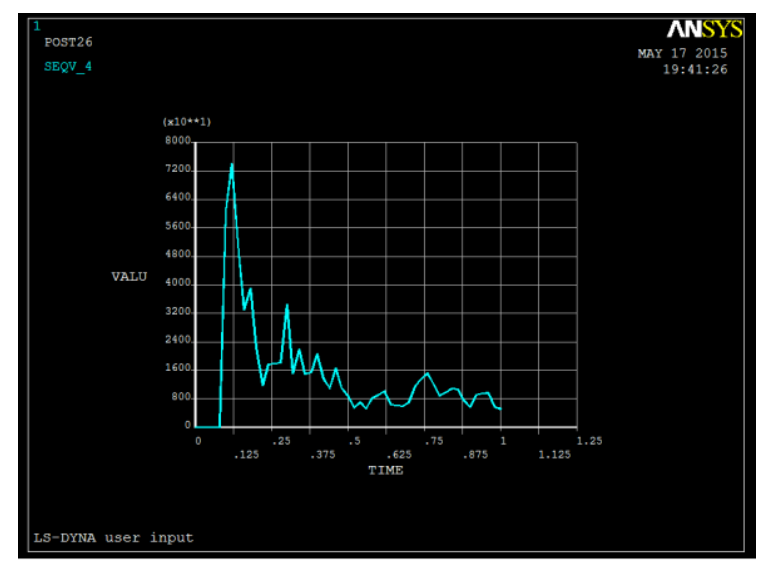

Fig-11: Stress Distribution Graph of Component
Graph shows in Fig 11, maximum stress distribution takes place due to random velocity in negative $y$-axis based on design model.

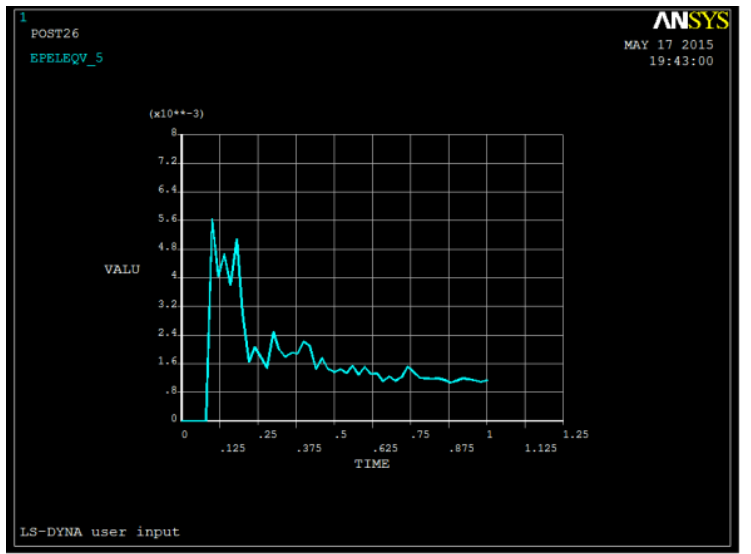

Fig-12: Strain Distribution Graph of Component

Graph shows in Fig 12, maximum strain distribution takes place due to random velocity in negative $y$-axis based on design model.

\subsection{CASE-2: Drop Test Analysis on Kinematic \\ Bilinear and Mild Steel Material}

Kinematic bilinear material is used for pen drive and mild steel is used for platform results are shows as below

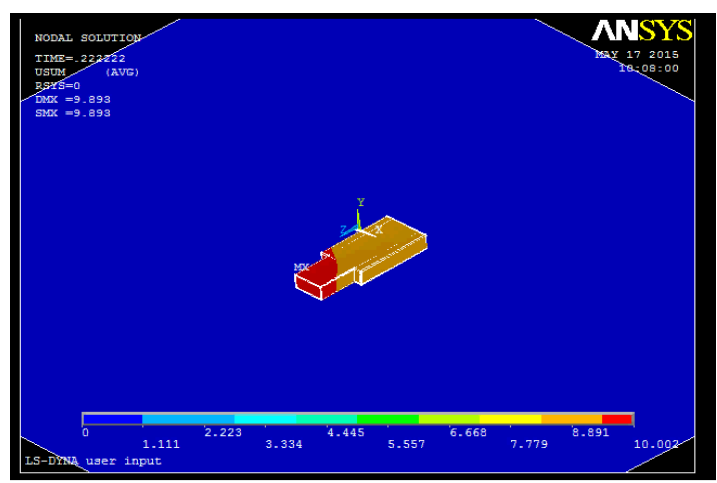

Fig-13: Displacement of Component

Fig -13 shows the maximum displacement of the component is $10.002 \times 10^{-2}$ inch $(0.003937 \mathrm{~mm})$ of initial velocity -100 inch/sec is falling on the plot form.

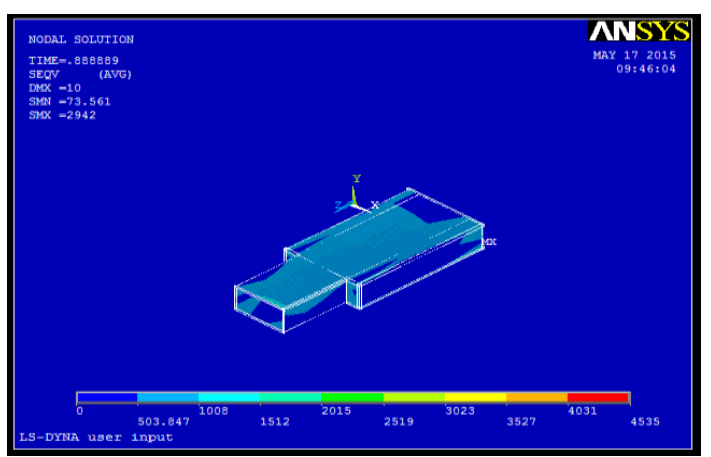

Fig-14: Stress Distribution of Component 
Fig -14 shows the maximum stress distribution in a component is $4535 \mathrm{psi}$ at initial velocity $-100 \mathrm{inch} / \mathrm{sec}$ is falling on the plot form.

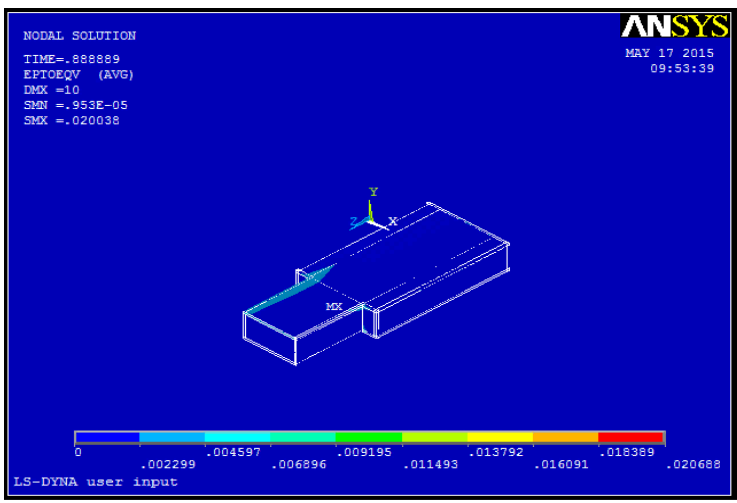

Fig-15: Strain Distribution of Component

Fig -15 shows the maximum strain distribution in a component is 0.020688 at initial velocity $-100 \mathrm{inch} / \mathrm{sec}$ is falling on the plot form.

\section{Graphs}

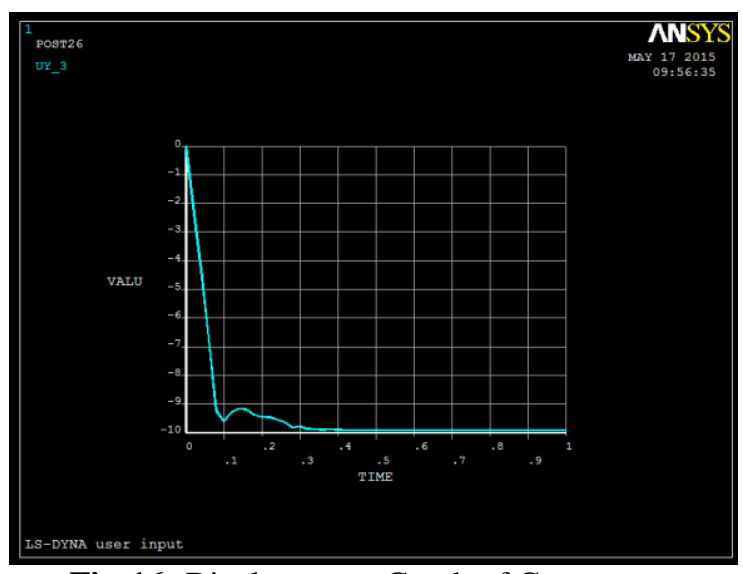

Fig-16: Displacement Graph of Component

Graph shows in Fig 16, maximum displacement takes place due to random velocity in negative y-axis based on design model.

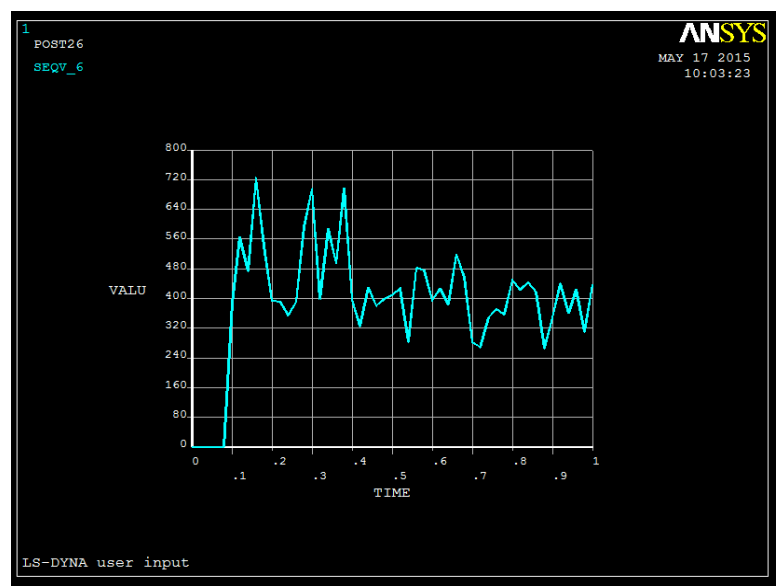

Fig-17: Stress Distribution Graph of Component
Graph shows in Fig 17, maximum stress distribution takes place due to random velocity in negative $y$-axis based on design model.

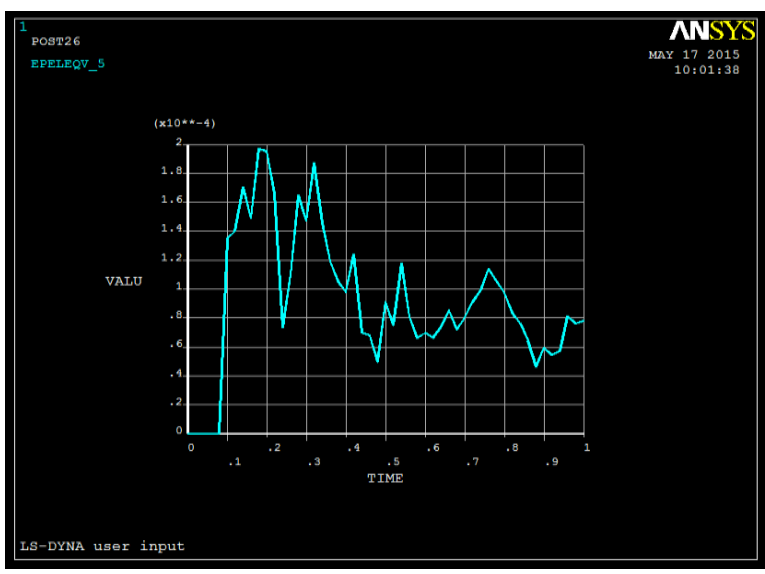

Fig-18: Strain Distribution Graph of Component

Graph shows in Fig 18, maximum strain distribution takes place due to random velocity in negative $\mathrm{y}$-axis based on design model.

\subsection{Discussion}

Table-2 Correlating Results

\begin{tabular}{|c|c|c|c|c|}
\hline Case & $\begin{array}{c}\text { Velocity, } \\
\text { (Inch/Sec) }\end{array}$ & $\begin{array}{c}\text { Displacement, } \\
\text { (Inch) }\end{array}$ & $\begin{array}{c}\text { Stress, } \\
(\text { Psi) }\end{array}$ & Strain \\
\hline 1 & -100 & $11.233 \times 10^{-2}$ & 572100 & 0.03432 \\
\hline 2 & -100 & $10.002 \times 10^{-2}$ & 4532 & 0.020688 \\
\hline
\end{tabular}

Table 2. shows that the case 1 mild steel material of a pen drive stress distribution occurs maximum above the proportion limit, it shows component is un safe. In the case 2 material is replaced by kinematic bilinear material has have less stress compare to the case 1 material.

\section{CONCLUSION}

The Structural analysis measurements is compared with the obtained stress levels using ANSYS. The induced stresses as obtained from the ANSYS calculations are compared with results obtained with the two materials. The results obtained by the analysis are very nearer to yielding strength as shown in table I and table II.

Summary of project is shown below

$>$ Modeling, meshing, applying boundary conditions and results are analyzing the structural safety of component using ANSYS

$>$ Initially carbon steel is used for the drop test analysis which shows higher stresses of around 572100 Psi, strain is 0.03432 , deformation show maximum $11.3 \mathrm{x}$ $10^{-2}$ in.

$>$ Later carbon steel material is replaced by kinematic inelastic material (Plastic material) to find the structural safety of component under drop test 
boundary conditions which shows less stresses of around 4532 Psi, strain is 0.020688 , deformation show maximum $10.002 \times 10^{-2}$ in.

$>$ Finally result shows that kinematic inelastic material (Plastic material) is good for pen drive.

\section{ACKNOWLEDGEMENTS}

I am deeply indebted to my parents, my family members and to my students for encouraging and helping me to prepare the project.

\section{REFERENCES}

[1] www.ansys.com, "Drop test simulation made easy with ANSYS simulation" by john Higgins presented conference on application engineer ANSYS, NIC.

[2] www.droptesting.com.

[3] www.dynaexamples.com.

[4] https://www.youtube.com/watch?v=RJfqSnM-uVU

[5] www.wildeanalysis.com

[6] www.deskeng.com

[7] www.fujixerox.com

[8] https://books.google.co.in/books?id

[9] www.scientific.net

[10] www.nenastran.com

[11] www.javelin-tech.com

[12] www.solidworks.com

[13] www.virtualsimutech.com

\section{BIOGRAPHIES}

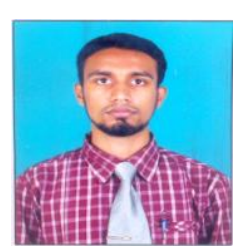

${ }^{1}$ Asst. Prof., Department of Mechanical Engineering, Ghousia College of Engineering, Ramanagaram, Karnataka, India

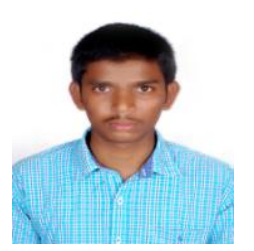

${ }^{2}$ Student, Department of Mechanical Engineering, Ghousia College of Engineering, Ramanagaram, Karnataka, India

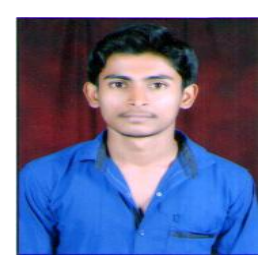

${ }^{3}$ Student, Department of Mechanical Engineering, Ghousia College of Engineering, Ramanagaram, Karnataka, India

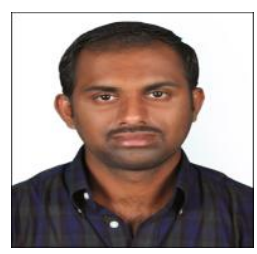

${ }^{4}$ Student, Department of Mechanical Engineering, Ghousia College of Engineering, Ramanagaram, Karnataka, India 